\title{
DISTRIBUSI DAN POLA SESAR DAERAH KEPALA BURUNG (PAPUA BARAT)
}

\author{
Oleh: \\ Imarotul Muflihah ${ }^{1}$
}

\begin{abstract}
ABSTRAK : Pergerakan tiga lempeng di Indonesia, yakni lempeng Asia, lempeng Indo-Australia dan lempeng Pasifik menimbulkan unsur-unsur tektonik yaitu gempa bumi. Hampir seluruh wilayah Indonesia mengalami aktifitas tektonik, salah satu wilayah yang mengalami tektonik aktif adalah daerah Kepala Burung, Papua Barat. Daerah ini diduga terdapat pertemuan tiga lempeng tersebut. Penelitian geologi dan evolusi daerah Kepala Burung dimulai beberapa tahun lalu oleh beberapa peneliti. Studi tentang pergerakan lempeng yang mempengaruhi Kepala Burung menjelaskan bahwa lempeng benua Indo-Australia pada saat ini bergerak relatif ke utara sedangkan lempeng samudera Pasifik bergerak ke barat-daya. Deformasi akibat tumbukan oblique kedua lempeng ini terekam pada sejarah tektonik Kepala Burung dan seluruh daratan New Guinea. Akibatnya pada daerah Kepala Burung ini sering terjadi aktifitas tektonik hampir setiap hari pada setiap tahunnya. Dari penjelasan geologi tersebut diduga terdapat sesar-sesar aktif yang mana perlu dikaji lebih lanjut mengenai sesar-sesar di daerah Kepala Burung tersebut.

Tahapan penelitian ini dilakukan tiga tahap. Pertama, Data gempabumi yang yang digunakan adalah data sekunder yang diperoleh dari database gempa internasional yang dikelola oleh United States Geological Services(USGS), dan dari global CMT yang berpusat di Amerika Serikat. Kedua, Dari data global CMT tercatat data-data berupa beach ball, strike, dip, slip/rake-nya sehingga dapat dilihat mekanisme sesar. Ketiga, Pemetaan persebaran gempabumi dengan menggunakan Arcview GIS 3.3. Setelah dilakukan tahap-tahap tersebut kemudian dilakukan analisis data.

Berdasarkan analisa data yang telah didapatkan dari hasil penelitian yang dilakukan, disimpulkan bahwa gempabumi yang terjadi di daerah Kepala Burung (Papua Barat) sebanyak 410 gempa, dan terdapat empat jenis sesar/patahan yaitu sesar geser, sesar naik, sesar turun dan sesar oblique. Jumlah sesar dari kejadian gempabumi tersebut adalah sebagai berikut : Sesar geser sebanyak 113 kali, sesar naik sebanyak 142 kali, sesar turun sebanyak 89 kali, sesar oblique sebanyak 73 kali. Dari jumlah sesar tersebut yang paling dominan di wilayah penelitian terjadi sesar naik.
\end{abstract}

Kata Kunci : Gempabumi, sesar/patahan, focal mechanism

\begin{abstract}
The movement of all three plates in Indonesia that are Asian plate, the IndoAustralian plate and Pacific plate tectonic elements cause earthquake. Almost all parts of Indonesia experience tectonic activity, one of the areas experiencing active tectonics is Kepala Burung region of West Papua. This area is alleged as meeting point of the three plates. Research geology and evolution in Kepala Burung region began a few years ago by some researchers. The study of plates movement affecting this region explains that the Indo-Australian continental plate is currently moving relative to the north while the Pacific oceanic plate moves to the southwest. Deformation due to the oblique collision of these plates are recorded on the tectonic history of Kepala Burung and the rest of the mainland of New Guinea. As a result, Kepala Burung region is frequent tectonic activity nearly every day of every year. Based on the description of the geology, it is suspected than active faults are exist which needs to be studied any further.

This study was conducted in three stage. First, the used earthquake data are secondary data obtained from the database of international earthquake administered by the United States Geological Service (USGS), and from the global CMT based in the United States. Second, the global CMT data recording the beach ball data, strike, dip, slip /rake to observe fault mechanism. Third, Mapping of earthquakes distribution by using ArcView GIS 3.3. After these stages are accomplished then the data is analyzed.

Based the data, it was concluded that the earthquake occurred 410 times in Kepala Burung region (West Papua). There are four types of fault / shear fracture that are sliding fault, reverse fault, down fault and oblique fault. The number of occurrence of earthquake faults are as follows: sliding fault
\end{abstract}

\footnotetext{
${ }^{1}$ Jurusan Fisika, Fakultas Sains dan Teknologi, UIN Maliki Malang
} 
as many as 113 times, reverse fault 142 times, the down fault 89 times, oblique faults 73 times. From the number of the most dominant fault in the study area occurred reverse fault.

Keyword : earthquake, fault/shear,focal mechanism

\section{PENDAHULUAN}

Indonesia merupakan salah satu negara yang mempunyai tingkat kegempaan yang tinggi, dikarenakan Indonesia merupakan daerah pertemuan tiga lempeng tektonik benua, yaitu:lempeng Asia bergerak dari utara ke selatan tenggara, lempeng Samudera Hindia Australia bergerak dari selatan menuju utara dan lempeng Pasifik yang bergerak dari timur ke barat. Akibat dari gerakan ketiga lempeng ini menimbulkan unsur-unsur tektonik lainnya seperti sesar/patahan lokal,

Gempabumi merupakan fenomena alam dimana terjadinya proses pelepasan energi yang terakumulasi selama kurun waktu tertentu secara tiba-tiba akibat adanya pergerakan lempeng teknonik di dalam bumi. Menurut teori tektonik lempeng, bagian luar bumi merupakan kulit yang tersusun atas lempeng-lempeng tektonik yang saling bergerak. Di bagian atas disebut lapisan litosfer merupakan bagian kerak bumi yang tersusun dari material yang kaku. Lapisan ini mempunyai ketebalan sampai kedalaman $80 \mathrm{~km}$ di daratan dan sekitar $15 \mathrm{~km}$ di bawah samudra. Lapisan di bawahnya disebut astenosfir yang berbentuk padat dan materinya dapat bergerak karena perbedaan tekanan [1]

Sesar merupakan rekahan yang mengalami geseran-geseran yang jelas. Pergeseran tersebut berkisar dari beberapa milimeter sampai ratusan meter sedangkan panjangnya mulai dari beberapa desimeter sampai hingga ribuan meter. Sesar dapat terjadi pada segala macam batuan dengan tipe yang beragam. Sesar pada struktur batuan dapat mengakibatkan perubahan maupun perkembangan topografi, mengubah aliran air dibawah dan diatas permukaan serta merusak stratigrafi batuan dan sebagainya [2]. Sesar merupakan penyebab terjadinya gempabumi.

Teori elastic rebound menyatakan bahwa gempabumi dihasilkan atau disebabkan oleh proses pergeseran pada kerak bumi sebagai akibat dari pelepasan mendadak dari strain elastic, yang melampaui kekuatan batuan. Strain elastik ini akan terakumulasi bila batauan mengalami deformasi secara terus-menerus dan semakin besar. Bila sesar terjadi bagian yang berseberangan akan bergeser memebentuk posisi kesetimbangan baru. Sedangkan energi yang dilaepaskan akan memebentuk panas dan atau vibrasi gelombang elastic [3].

Rengkahan/sesar bumi adalah pecahan pada keranya, dimana melaluinya terjadi pergerakan pada kedua sisi level rengkahannya, baik gerakan horizontal maupun vertikal dan diagonal secara signifikan. Dimensi rengkahannya sangat beragam, ada gerakannya yang hampir tidak dapat dirasakan dan ada gerakan yang dapat dirasakan melalui tingkatnya mencapai tingkat tinggi, yang mana peristiwa gerak aktif rengkahan bumi tersebut sering dikenal dengan istilah gempa bumi [4].

Mekanisme sumber sesar dari gempa bumi tersebut yaitu dapat diketahui dengan melihat posisi titik pusat lingkaran terdapat pada daerah kompresi (diarsir) atau pada daerah dilatasi (tanpa arsiran). Dengan model bidang patahan dari focal mechanism, maka akan terlihat jelas tipe sesar yang menyebabkan gempa bumi itu terjadi [5]. 
Penelitian ini bertujuan untuk mengetahui jenis patahan di atas Kepala Burung dan mengetahui zona-zona yang terkena dampak aktifitas tektonik. Penelitian ini dimulai pada bulan Mei 2013 sampai September 2013 di Laboratorium Geofisika UIN Malang. Data gempa yang digunakan dalam penelitian ini berupa data sekunder dari United States Geological Services(USGS) dan Global CMT yang mana berupa data seismik yang periode 1976-2012 di wilayah Kepala Burung, Papua Barat. serta untuk mengetahui sebaran gempa dilakukan pemetaan dengan menggunakan Arcview GIS 3.3.

Penelitian ini dilakukan dengan mengambil data gempa bumi dangkal antara tahun 1976 sampai 2012. Dari kejadian gempa yang terseleksi kemudian diteliti untuk di analisa karakteristik gempa-gempa yang ada di Kepala Burung, Papua Barat.

\section{HASIL DAN PEMBAHASAN}

Berdasarkan data gempa yang diperoleh terdapat 417 kejadian gempa. Dari data gempa tersebut diperoleh bentuk-bentuk sesar yang bervariasi yang kemudian dibagi menjadi tiga zona berdasarkan pada pembagian bujurnya yaitu pada bujur $100^{\circ}-130^{\circ} \mathrm{BT}$, $130^{\circ}-140^{\circ}$ BT dan $140^{\circ}-150^{\circ}$ BT. Data-data tersebut ditunjukkan sebagai berikut :

Tabel 1. Sesar Pada Bujur $100^{0}-130^{\circ}$ BT

\begin{tabular}{|c|c|c|c|}
\hline Bujur & Beachball & Jenis Sesar & Jumlah \\
\hline \multirow{4}{*}{$100^{0}-130^{\circ} \mathrm{BT}$} & & $\begin{array}{c}\text { sesar geser /sesar mendatar } \\
\text { (strike slip) }\end{array}$ & 77 \\
\hline & & $\begin{array}{c}\text { sesar naik } \\
\text { (reverse fault) }\end{array}$ & 121 \\
\hline & & $\begin{array}{c}\text { sesar turun } \\
\text { (normal fault) }\end{array}$ & 45 \\
\hline & & sesar oblique & 32 \\
\hline
\end{tabular}

Gempa pada bujur $100^{\circ}-130^{\circ}$ BT terdapat 275 gempa sepanjang tahun 1976 hingga tahun 2012. Sesar-sesar yang berada pada bujur ini diantaranya 77 sesar mendatar/strike slip fault, 121 sesar naik/ reverse fault, 45 sesar turun/ normal fault dan 32 sesar oblique. Adapun yang paling dominan pada bujur $100^{\circ}-130^{\circ} \mathrm{BT}$ adalah sesar naik/reverse fault. 


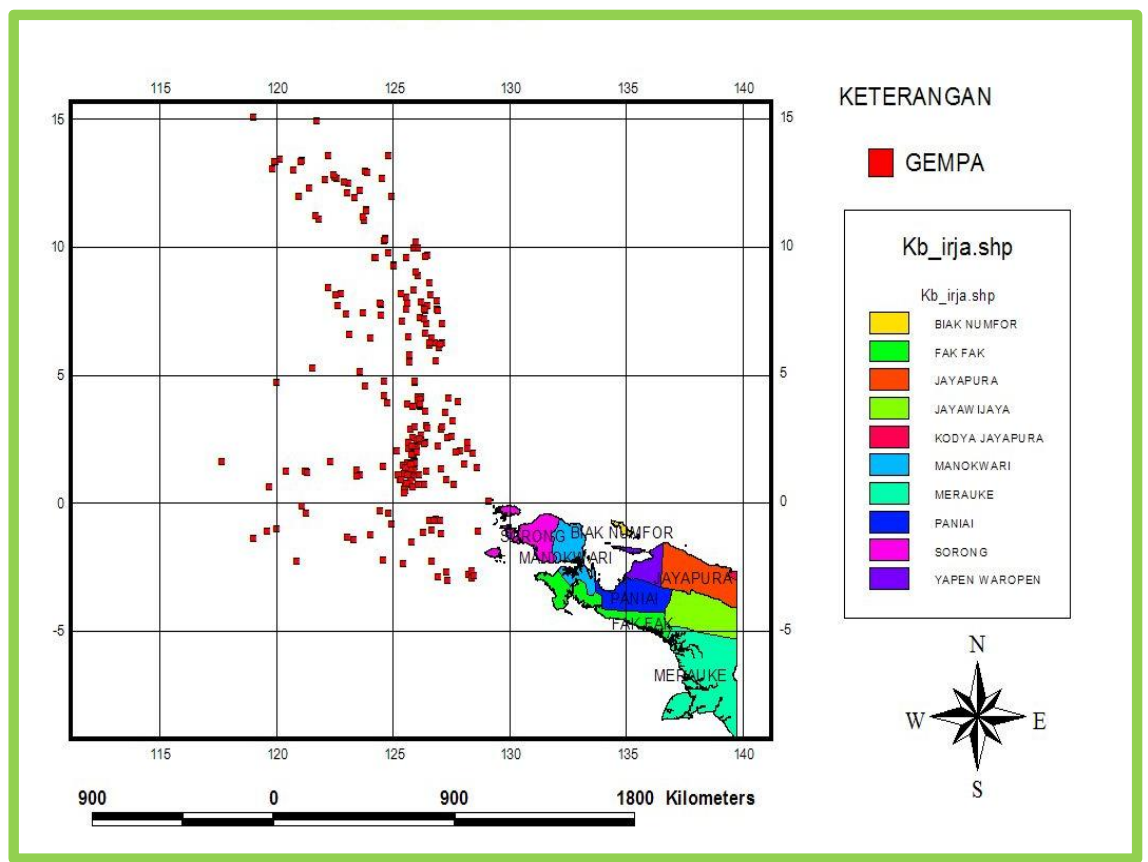

Gambar 1 : Peta Sebaran Gempa Pada Bujur $100^{\circ}-130^{\circ}$ BT

Peta tersebut menunjukkan bahwa kejadian-kejadian gempa pada bujur $100^{0}-130^{\circ} \mathrm{BT}$ tersebut terlihat gempa lebih banyak tersebar ke arah barat dan ke utara. Sebaran yang menuju arah barat lebih mendekat ke pulau Seram laut Mollusca, agak ke selatan mengarah ke laut Banda sedangkan yang condong ke utara lebih mengarah ke pulau caroline, Philipina.

Tabel 2. Sesar Pada Bujur $130^{\circ}-140^{\circ}$ BT

\begin{tabular}{|c|c|c|c|}
\hline Bujur & Beachball & Jenis Sesar & Jumlah \\
\hline & & $\begin{array}{c}\text { sesar geser /sesar mendatar } \\
\text { (strike slip) }\end{array}$ & 24 \\
\hline & & $\begin{array}{c}\text { sesar naik } \\
\text { (reverse fault) }\end{array}$ & 16 \\
\hline & & $\begin{array}{c}\text { sesar turun } \\
\text { (normal fault) }\end{array}$ & 9 \\
\hline & & sesar oblique & 6 \\
\hline
\end{tabular}


Gempa pada bujur $130^{\circ}-140^{\circ}$ BT terdapat 55 kali kejadian gempa dengan sesar-sesar yang bervariasi diantaranya 24 sesar mendatar/strike slip fault, 16 sesar naik/reverse fault, 9 sesar turun/ normal fault dan6 sesar oblique. Adapun yang paling dominan pada bujur $130^{\circ}-140^{\circ}$ BT adalah sesar geser/sesar mendatar.

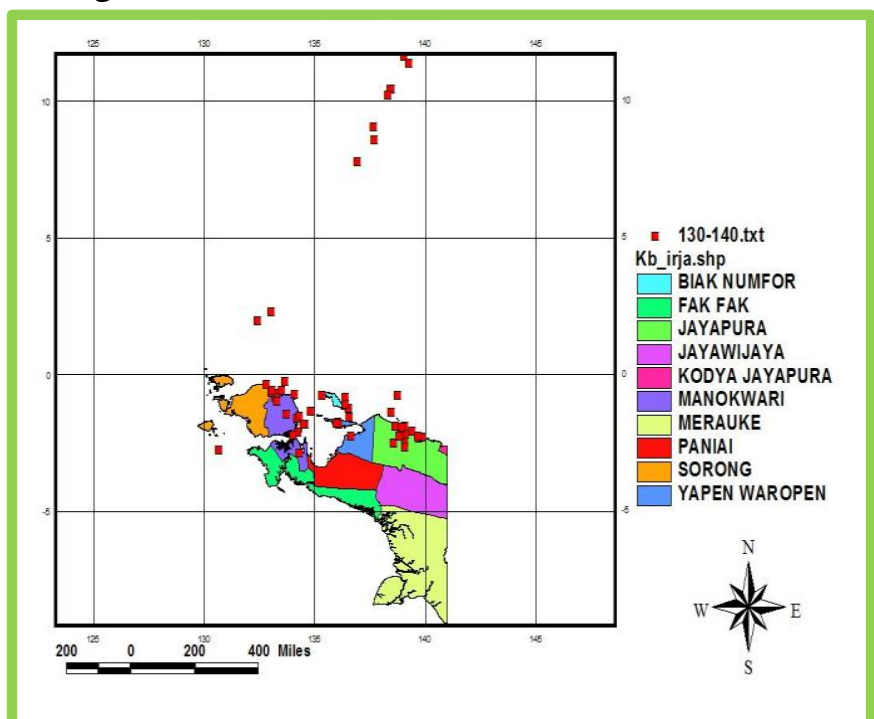

Gambar 2. Peta Sebaran Gempa Pada Bujur $130^{\circ}-140^{\circ}$ BT

Peta tersebut menunjukkan bahwa kejadian-kejadian gempa pada bujur $130^{\circ}-140^{\circ} \mathrm{BT}$ tersebut terlihat gempa lebih banyak tersebar ke arah timur dan ke utara. Sebaran yang menuju arah timur lebih mendekat ke daerah Yapen waropen, Jayapura dan laut Bismark sedangkan yang condong ke utara lebih mengarah ke Samudera Pasifik.

Tabel 3. Sesar Pada Bujur $140^{0}-150^{\circ}$ BT

\begin{tabular}{|c|c|c|c|}
\hline Bujur & Beachball & Jenis Sesar & Jumlah \\
\hline & & $\begin{array}{l}\text { sesar geser /sesar mendatar } \\
\text { (strike slip) }\end{array}$ & 30 \\
\hline & & $\begin{array}{c}\text { sesar naik } \\
\text { (reverse fault) }\end{array}$ & 14 \\
\hline $140^{0}-150^{0} \mathrm{BT}$ & & $\begin{array}{l}\text { sesar turun } \\
\text { (normal fault) }\end{array}$ & 34 \\
\hline & & sesar oblique & 9 \\
\hline
\end{tabular}

Gempa pada bujur $140^{\circ}-150^{\circ}$ BT tercatat ada 87 kejadian gempa. sesar-sesar yang berada pada bujur ini diantaranya 30 sesar mendatar/strike slip fault, 14 sesar naik/reverse 
fault, 34 sesar turun/ normal fault dan 9 sesar oblique. Adapun yang paling dominan pada bujur $140^{\circ}-150^{\circ} \mathrm{BT}$ adalah sesar geser/sesar mendatar.

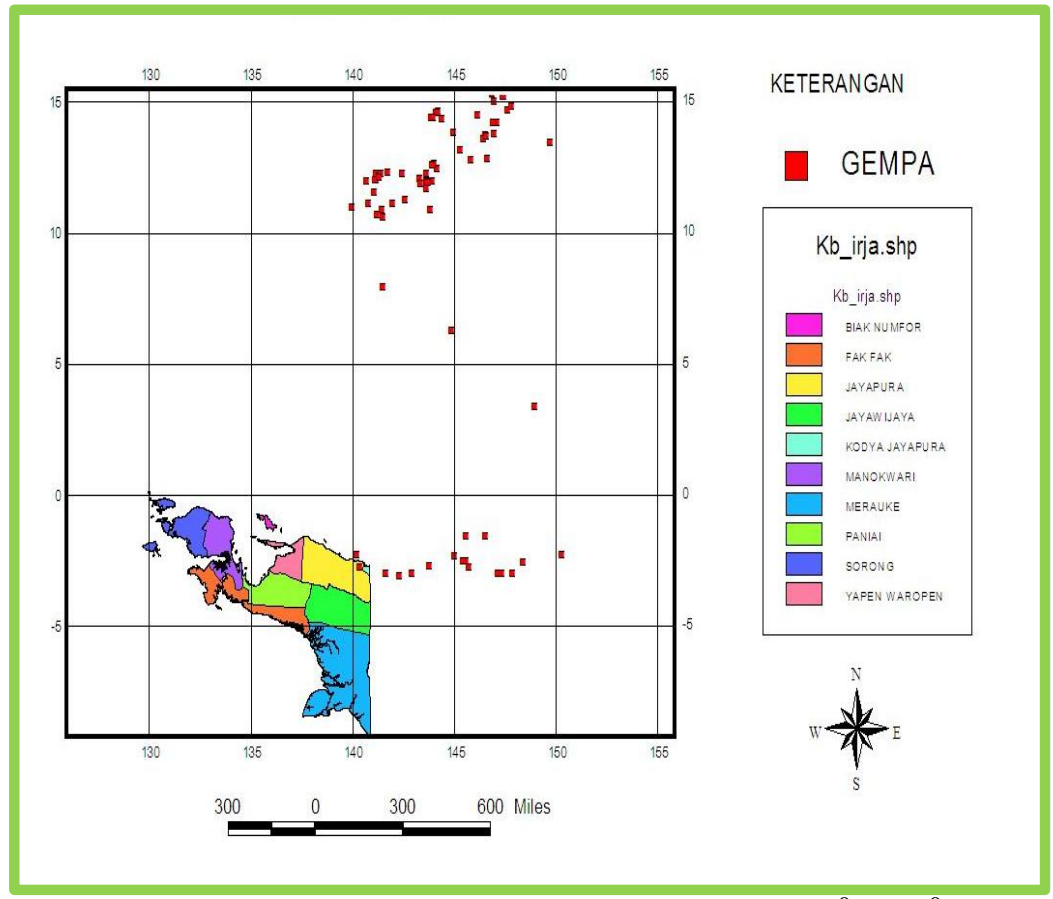

Gambar 3. Peta Sebaran Gempa Pada Bujur $140^{\circ}-150^{\circ}$ BT

Peta pada gambar 3, tersebut menunjukkan bahwa kejadian-kejadian gempa pada bujur $140^{\circ}-150^{\circ} \mathrm{BT}$ tersebut terlihat gempa lebih banyak tersebar ke arah timur dan ke utara. Sebaran yang menuju arah timur lebih mendekat ke daerah Jayapura, Papua New Guinea dan laut Bismark sedangkan yang condong ke utara lebih mengarah ke Samudra Pasifik dan Philipina.

Daerah Kepala Burung, Papua Barat merupakan daerah pertemuan tiga lempeng/triple junction (lempeng Asia, lempeng Indo-Australia dan lempeng Pasifik). Pergerakan ketiga lempeng tadi dapat menimbulkan patahan atau sesar yaitu pergeseran antara dua blok batuan baik secara mendatar, ke atas maupun relatif ke bawah blok lainnya. Sehingga . Struktur geologi yang terdapat pada daerah Kepala Burung (Papua Barat) berupa patahan atau sesar (fault.)

Patahan atau sesar ini merupakan perpanjangan gaya yang ditimbulkan oleh gerakangerakan lempeng utama. Patahan atau sesar inilah yang akan menghasilkan gempa bumi di daratan dan tanah longsor. Akibatnya, bangunan yang ada di atas zona patahan ini sangat rentan mengalami runtuhan. 


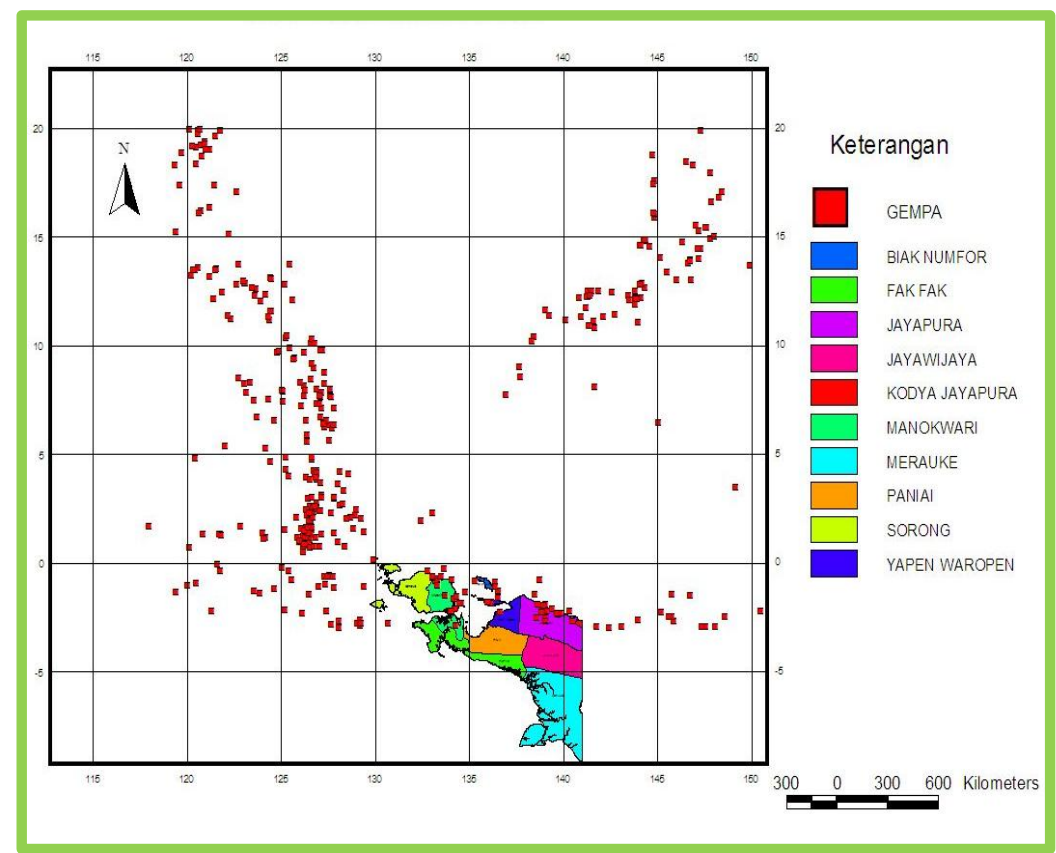

Gambar 4. Peta Keseluruhan Sebaran Gempa Pada Bujur $100^{0}$ BT - $150^{0}$ BT

Tampak dari peta tersebut menunjukkan bahwa sebagian besar pusat gempa tersebut tersebar membentuk pola memanjang ke arah utara, dan beberapa pusat gempa membentuk pola memanjang kea rah timur sepanjang sistem sesar Sorong. Peta tersebut menunjukkan bahwa pada lintang $0^{\circ} \mathrm{LS}-3^{0} \mathrm{LS}$ dan pada bujur $120^{\circ} \mathrm{BT}-150^{\circ} \mathrm{BT}$ sesar yang paling dominan adalah sesar geser. Sesar geser disebut juga batas transform, yaitu terjadi bila dua lempeng tektonik yaitu lempeng Eurasia dan lempeng Indo-Australia bergerak saling sejajar namun berlawanan arah.

Pada lintang $0^{0} \mathrm{LU}-20^{\circ} \mathrm{LU}$ dan bujur $125^{\circ} \mathrm{BT}-130^{\circ} \mathrm{BT}$ sesar yang paling dominan adalah sesar naik (reverse fault), dimana efek dari sesar naik menimbulkan penunjaman (subduksi) atau konvergensi. Konvergensi mengakibatkan adanya dua lempeng tektonik yaitu lempeng Eurasia dan lempeng Pasifik yang saling menumbuk satu sama lain.

Pada lintang $5^{0} \mathrm{LU}-20^{\circ} \mathrm{LU}$ dan bujur $135^{\circ} \mathrm{BT}-150^{\circ} \mathrm{BT}$ sesar yang paling dominan adalah sesar turun (normal fault), dimana efek dari sesar ini menimbulkan pemekaran pada daerah tersebut. Pemekaran (divergensi) terjadi pada dua lempeng tektonik yaitu lempeng Eurasia dan lempeng Indo-Australia yang bergerak saling menjauh ketika sebuah lempeng tektonik pecah, lapisan litosfer menipis dan terbelah.

\section{KESIMPULAN}

1. Jenis patahan yang terdapat di daerah Kepala Burung adalah sesar geser, sesar naik, sesar turun dan sesar oblique. Dari 417 kejadian gempa yang terseleksi berdasarkan kedalamannya yaitu pada kedalaman kurang dari 60 kilometer (gempa dangkal) diperoleh jumlah sesar sebanyak 131 merupakan sesar geser, 151 sesar naik, 88 sesar turun serta 47 sesar oblique. Adapun yang paling dominan adalah berupa sesar naik. Sesar naik mengakibatkan daerah atau zona tersebut mengalami subduksi atau penunjaman. 
2. Zona-zona yang terkena dampak akibat aktifitas tektonik di antaranya adalah ke arah utara lebih mengarah ke pulau caroline, Philipina dan samudera Pasifik. Ke arah timur mengarah ke Jayapura, Papua New Guineadan laut Bismark . Ke arah barat mendekat ke pulau Seram dan laut Mollusca, agak ke selatan mengarah ke laut Banda.

\section{DAFTAR PUSTAKA}

[1] Afnimar. 2009. Seismologi. Bandung: ITB

[2] Elnashai, Amr and Di Sarno, Luigi. 2008. Fundamentals of Earthquake Engineering. West Sussex. Wiley \& Sons, Ltd

[3] Fouch. 2006. Geotectonic.

[4] El Naggar, Zaghloul. 2010. Ayat-Ayat Kosmos dalam al-Qur'an al-Karim jilid 23.Jakarta: Shorouk International Bookshop

[5] Ulfa Wulantari.2010. Penentuan Mekanisme Sumber Sumtera Barat Berdasarkan Gelombang P. Malang : Universitas Brawijaya 